\title{
Growth of Sulphate-reducing Bacteria by Fumarate Dismutation
}

\author{
By J. D. A. MILLER* AND D. S. WAKERLEY \\ National Physical Laboratory, Teddington, Middlesex
}

(Received 7 October 1965)

\section{SUMMARY}

Desulfovibrio gigas and several strains of $\boldsymbol{D}$. desulfuricans grew by fumarate dismutation in a sulphate-free medium. Two strains of $D$. desulfuricans grown in a chemically defined medium formed succinate, malate and acetate during fumarate dismutation. Sulphate reduction by these strains, though not by $D$. gigas, was almost completely inhibited in presence of fumarate as alternative electron acceptor. The anomalous behaviour of $D$. gigas was reflected to some extent by the hydrogen absorption coefficients for fumarate and sulphate reduction. Effects of fumarate media on the morphology of one strain are recorded.

\section{INTRODUCTION}

Under natural conditions the sulphate-reducing bacteria appear to utilize sulphate as terminal electron acceptor in the assimilation of organic substances, and have been shown (Postgate, 1951) to reduce certain other sulphur-containing anions in culture. Growth on pyruvate in the absence of sulphur compounds has been reported for strains of Desulfovibrio desulfuricans (Postgate, 1952) and Clostridium nigrificans (Postgate, 1963); Senez \& Pascal (1961) and Baker, Papiska \& Campbell (1962) obtained growth of various strains of $D$. desulfuricans on choline in absence of sulphate. Grossman \& Postgate (1955) studied sulphate-free metabolism of malate and fumarate, not accompanied by growth, in $D$. desulfuricans strain El Agheila z. The present paper reports the discovery that Desulfovibrio gigas and a number of strains of $\boldsymbol{D}$. desulfuricans are able to grow by dismutation of fumarate, i.e. by a Cannizzaro-type reaction which involves the simultaneous oxidation and reduction of the substrate.

\section{METHODS}

Organisms. Twenty-three strains of sulphate-reducing bacteria were obtained as freeze-dried ampoules from the National Collection of Industrial Bacteria (NCIB). The strain names are followed by the NCIB number.

(1) Mesophiles (growth temperature $30^{\circ}$ ).

(a) Desulfovibrio gigas, a fresh-water strain (NCIB 9332).

(b) D. desulfuricans, salt-water strains : El Agheila A, 8309; Norway 4, 8310; New Jersey sw-8, 8315; New Jersey sw-3, 8316; California 29:137:5, 8326; Texas 29:12:B, 8328; Australia, 8329; California 43:63, 8364; El Agheila 4, 8396; Venezuela, 8399; Aberdovey, 9492.

* Present address: Department of Chemical Engineering, Manchester College of Science and Technology, Manchester 1. 
(c) D. desulfuricans, fresh-water strains: Teddington R, 8312; Denmark, 8456; Woolwich, 8457; Byron, 8458.

(2) Thermophiles (growth temperature $55^{\circ}$ ). Strains of Clostridium nigrificans, all fresh-water strains : Holland cr, 8356; Delft 48 T, 8357; Delft 3 T, 8359; Delft 13 T, 8360 ; Delft 15 T, 8361 ; unnamed strains 8706 and 8788 .

Maintenance of stock cultures. Cultures were raised from the freeze-dried condition at $30^{\circ}$ or $55^{\circ}$, as appropriate, in the medium of Baars (1930) containing $1.0 \mathrm{~g}$. Difco yeast extract/l. and $5 \mathrm{~mm}$-cysteine hydrochloride. Sodium chloride, $25 \mathrm{~g}$./l., was added for salt-water organisms. Details of the preparation, sterilization and $\mathrm{pH}$ adjustment of this medium are given elsewhere (Saleh, Macpherson \& Miller, 1964). Stock cultures of the mesophilic strains were maintained in Postgate's modification of the medium C of Butlin, Adams \& Thomas (1949; see Baker et al. 1962) containing cysteine, and $\mathrm{NaCl}$ where necessary. The thermophilic strains grew better in Baars's medium + yeast extract, in which medium stock cultures were therefore maintained. Subcultures were made weekly. Stock and experimental cultures were grown in Pyrex test tubes or Erlenmeyer flasks plugged with cottonwool and incubated in McIntosh \& Fildes anaerobic jars under an atmosphere of $\mathbf{N}_{2}$. Frequent tests were made on stock and experimental cultures for aerobic and anaerobic contaminants (Postgate, 1953).

Experimental media. Two types of media were used:

(1) A basal medium consisting of modified medium $\mathrm{C}$ with sodium lactate, $\mathrm{Na}_{2} \mathrm{SO}_{4}$ and $\mathrm{MgSO}_{4}$ omitted, and containing $8 \mathrm{~mm}-\mathrm{MgCl}_{2} \cdot 6 \mathrm{H}_{2} \mathrm{O}$. To this basal medium was added $50 \mathrm{~mm}$-sodium lactate $(\mathrm{L}), 50 \mathrm{~mm}$-sodium fumarate $(\mathrm{F})$, or $50 \mathrm{~mm}-\mathrm{Na}_{2} \mathrm{SO}_{4}(\mathrm{~S})$, singly or in admixture. Since the basal medium contained yeast extract $(\mathrm{Y})$, the various media derived from this basal medium were designated FY, LFY, FSY and LSY.

(2) A basal medium consisting of the chemically-defined medium of Macpherson \& Miller (1963), also with lactate and sulphate omitted, and containing 0.25 mm$\mathrm{MgCl}_{2} \cdot \mathbf{6} \mathrm{H}_{2} \mathrm{O}$. Similar additions of lactate, fumarate or sulphate were made, the resulting media being designated F, LF, FS and LS.

$\mathrm{FeSO}_{4}$ was added to all experimental media to $25 \mu \mathrm{M}$. This amount was sufficient for assimilatory sulphur and iron metabolism but insufficient for discernible growth by sulphate reduction to occur.

Chromatography. Dicarboxylic acids in culture filtrates were identified by descending chromatography on Whatman no. 1 paper using a tert-amyl alcohol+ chloroform + water + formic acid $(50+50+50+18 \cdot 75$, by vol.) solvent system or a di-isopropyl ketone + water + formic acid $(50+50+13 \cdot 3$ by vol. $)$ system. Oxaloacetate was searched for with a $n$-butanol + water + formic acid $(95+100+5$ by vol.) system (Magasanik \& Umbarger, 1950) and a methylethylketone + acetone + water + formic acid $(80+4+12+2$ by vol.) system (Reio, 1959). Acetate, removed by steam distillation from the acidified culture filtrate, was identified by using $n$-butanol $+1 \cdot 5 \mathrm{~N}-\mathrm{NH}_{4} \mathrm{OH}(1+1$ by vol. $)$ solvent, and by the standard chemical tests (Feigl, 1960).

Sulphide estimation. For estimation of sulphide formed in cultures, $\mathrm{H}_{2} \mathrm{~S}$ in the gas phase of the anaerobic jars was first displaced by a stream of $\mathrm{N}_{2}$, absorbed in $1 \%$ $(w / v)$ cadmium acetate solution and the precipitated CdS determined iodometrically (Wilson \& Wilson, 1959). Dissolved and precipitated sulphide was then removed 
from the acidified and heated cultures by a stream of $\mathrm{N}_{2}$ and estimated as above.

Manometry. Measurement of hydrogenase activity was made at $37^{\circ}$ in the Warburg respirometer following the procedure of Littlewood \& Postgate (1956) except that $15 \%(w / v) \mathrm{KOH}$ was used as absorbent for $\mathrm{H}_{2} \mathrm{~S}$ and $\mathrm{CO}_{2}$.

Dry weight determinations. Dry weights for the sulphide estimations were determined by centrifuging portions of cultures at about $15,000 \mathrm{~g}$ for $10 \mathrm{~min}$., washing and drying the bacteria at $105^{\circ}$ to constant weight. For manometry, suspensions of organisms were standardized turbidimetrically and related to a calibration curve of strain Hildenborough (8303) for the purpose of calculating $-Q_{\mathrm{H}_{2}}$ values.

\section{RESULTS}

Growth of various sulphate-reducing bacteria in fumarate media

Tubes of LFY and FY media were inoculated from stock cultures. The former medium was intended to test for the function of fumarate as terminal electron acceptor in place of sulphate, while growth in FY medium in absence of $\mathrm{H}_{2}$ would indicate the simultaneous utilization of fumarate as electron donor, carbon source and electron acceptor. Where growth occurred, that in the fifth subculture into the experimental medium is shown rough-quantitatively in Table 1. Eleven mesophilic

\section{Table 1. Growth of sulphate-reducing bacteria in fumarate media}

Growth in the fifth subculture in experimental medium was recorded; that which was judged by eye to be about equal to growth in medium $\mathbf{C}$ was designated +++ . For explanation of symbols denoting media see Methods.

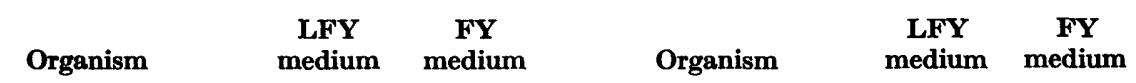

\begin{tabular}{|c|c|c|c|c|c|}
\hline D. gigas & - & $++t$ & \multicolumn{3}{|c|}{ D. desulfuricans fresh-water strains } \\
\hline \multicolumn{3}{|c|}{ D. desulfuricans salt-water strains } & Teddington $\mathbf{R}$ & +++ & +++ \\
\hline G1 Agheila A & $+t$ & $t+$ & Denmark & - & - \\
\hline Norway 4 & +++ & ++ & Woolwich & - & - \\
\hline New Jersey sw-8 & \pm & ++ & Byron & $++t$ & $++t$ \\
\hline New Jersey sw-3 & $=$ & ++ & C. nigrificans & & \\
\hline California 29:187:5 & +++ & +++ & Holland CT & - & - \\
\hline Texas 29:12:B & - & . & Delft 48T & - & - \\
\hline Australia & + & + & Delft 3T & - & - \\
\hline California 43: 63 & ++ & $++t$ & Delft 13T & - & - \\
\hline El Agheila 4 & ++ & - & Delft 15 $\mathrm{T}$ & - & - \\
\hline Venezuela & - & +++ & 8706 & - & - \\
\hline Aberdovey & - & - & $\mathbf{8 7 8 8}$ & - & - \\
\hline
\end{tabular}

strains dismuted fumarate; five of these grew less well or not at all in presence of lactate, for a reason not at present understood, while the converse was true for only one strain. No thermophilic strain grew in either medium. The trace amount of sulphate present was insufficient to support discernible growth when fumarate was omitted and lactate added.

Fumarate utilization in a chemically defined medium. To eliminate the possibility that fumarate dismutation was dependent on the presence of yeast extract, the two fresh-water strains which grew in LFY and FY media (Teddington $R$ and Byron) 
were later subcultured into both LF and F media. Heavy growth of both strains persisted through indefinite subculture in either medium.

\section{Products of fumarate metabolism}

Identification of metabolic end-products was done on filtrates of cultures of the fresh-water strains, since in these cases no desalting was necessary before chromatography. Succinate and acetate were present in $\mathbf{F}$ and LF cultures of Teddington $R$ and Byron; traces of malate, confirmed by the colour reaction with ammoniacal $\mathrm{AgNO}_{3}$ (Buch, Montgomery \& Porter, 1952), were found in some cultures in $\mathrm{F}$ medium. Oxaloacetate was not detected. No growth of the Teddington $\mathrm{R}$ strain occurred in a chemically-defined medium containing succinate as sole carbon source, and sulphate; malate was dismuted in sulphate-free medium by this and certain other strains (Elford, Miller \& Wakerley, in preparation).

\section{Sulphide production during growth in presence of fumarate}

It seemed of interest to determine whether sulphate reduction occurred in the presence of fumarate as an alternative electron acceptor. Strain Teddington $\mathbf{R}$ and Desulfovibrio gigas were inoculated into $200 \mathrm{ml}$. portions of FSY medium and into controls of LSY medium. The cultures were analysed for sulphide before reaching the maximum extinction attainable in FY medium by the strain concerned. The results of the analyses are given in Table 2.

Table 2. Formation of sulphide during growth of sulphate-reducing bacteria

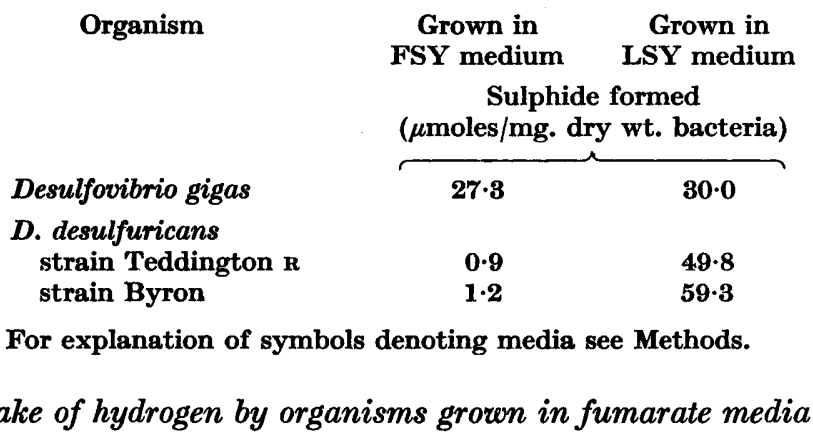

The results of $-Q_{\mathbf{H}_{2}}$ determinations for fumarate and sulphate reduction are shown in Table 3. A curious feature was that ${Q_{\mathbf{H}_{\mathbf{2}}}}_{\text {tumarate }}$ was more than ten times greater in strain Teddington $\mathrm{R}$ grown in LSY than in FSY medium. Desulfovibrio gigas has already been reported (Le Gall, 1963) to be hydrogenase-positive; its $-Q_{\mathrm{H}_{2}}$ for sulphate reduction was markedly higher than those usually obtained with strains of $D$. desulfuricans.

\section{Morphology and pigmentation of strain Teddington $R$ in fumarate media}

The description of strain Teddington $R$ lodged with the NCIB states that it is non-motile, with a tendency to pleomorphism. In the present work, organisms from cultures in lactate + sulphate medium (LS) were found to be normal vibrios or short spirilla, of mean dimensions about $1.8 \mu \times 0.7 \mu$, and some showed the typical progressive motility of, for example, the Hildenborough strain (NCIB 8303). To rule 
out contamination of our stock, cultures were raised from single organisms, both motile and non-motile, obtained from a culture in LS medium. A roughly similar proportion of motile to non-motile organisms was found in all these clones.

In LF medium the morphology was much the same as in LS medium. In F medium the organisms were rods of up to $3 \cdot 3 \mu \times 0.7 \mu$, often with no detectable curvature, a few being motile. In FS medium the rods were longer (up to $6 \cdot 2 \mu$ ), occasionally motile, with a tendency to form chains (non-motile) of up to four organisms. Only normal black colonies developed when these morphologically aberrant organisms were inoculated into Postgate's (1953) solid test medium.

Organisms from all these media showed a strong absorption band at about $553 \mathrm{~m} \mu$ typical of reduced cytochrome $c_{3}$ in the Hartridge reversion spectroscope, and gave a positive reaction to the desulfoviridin test (Postgate, 1959).

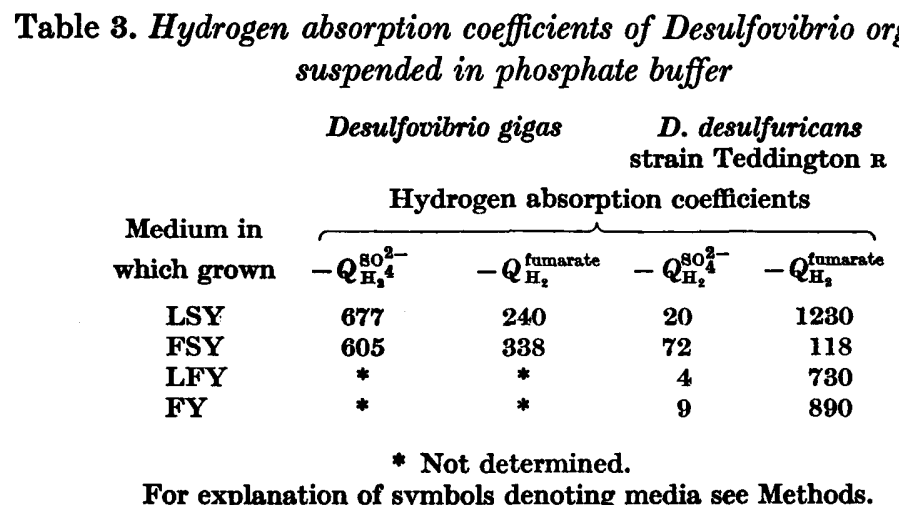

\section{DISCUSSION}

Grossman \& Postgate (1955) reported growth of Desulfovibrio desulfuricans strain El Agheila $z$ in an FSY-type medium; organisms suspended in phosphate buffer metabolized fumarate in absence of sulphate. Two strains have now been shown to grow by fumarate dismutation through indefinite subculture in a chemically-defined medium containing only trace amounts of sulphate; this nutritional pathway appears to be of common occurrence amongst the mesophilic sulphate-reducing bacteria, including the aberrant Norway 4 strain of $D$. desulfuricans (Miller \& Saleh, 1964) and the recently-described species D. gigas (Le Gall, 1963). The detection of succinate, malate and acetate as end-products of growth suggests the existence of a metabolic pathway: fumarate $\rightarrow$ malate $\rightarrow$ lactate $\rightarrow$ pyruvate $\rightarrow$ acetate at the expense of reduction of some of the substrate to succinate (compare Grossman \& Postgate, 1955). Hydrogen is not necessary for this sulphatefree growth. The mode of fumarate oxidation in sulphate-reducing bacteria is clearly different from that in Acetobacter xylinum, investigated by Benziman \& Abeliovitz (1964), a characteristic of which is oxaloacetate accumulation.

Fumarate can act as an alternative electron acceptor to sulphate for growth reactions in Teddington $\mathrm{R}$ and Byron (the only strains of $\boldsymbol{D}$. desulfuricans examined in this connexion) even when sulphate is present: sulphide production was almost completely suppressed in presence of fumarate, and succinate appeared among the 
end-products of metabolism. Such preferential use of fumarate would be expected from theoretical considerations, though Grossman \& Postgate (1955) found that small additions of fumarate to suspensions of strain El Agheila z organisms in phosphate buffer under $\mathbf{H}_{2}$ increased the rate of sulphate reduction, in contrast to its effect on strains Teddington $\mathrm{R}$ and Byron in a nutrient medium under $\mathrm{N}_{2}$. In the case of $D$. gigas, however, sulphide production per unit dry wt. of bacteria formed was roughly the same in FSY as in LSY medium (see Table 2), and a relatively small amount of succinate appeared on chromatograms of culture filtrates. The much lower values for $-Q_{\mathrm{B}_{\mathbf{8}}}^{\mathrm{sos}-}$ than for $-Q_{\mathrm{H}_{\mathbf{s}}}^{\text {tumarate }}$ in strain Teddington $\mathrm{R}$, and the converse for $D$. gigas (Table 3 ), may have a bearing on this observation, though Teddington $\mathbf{R}$ organisms grown in FSY medium actually had an unusually high $-Q_{\mathrm{H}_{3}}^{\mathrm{sog}}-$ value while only minute traces of sulphide were produced during growth in this medium. It appears that in the case of the sulphate reducers the behaviour of resting organisms towards oxidizable or reducible substrates may sometimes be quite different from that during growth.

The original description of strain Teddington $\mathrm{R}$ as non-motile is evidently incorrect; we have confirmed that it is pleomorphic, though not in lactate + sulphate medium.

We are indebted to Miss Lynette Elford and Miss Janet Hughes for technical assistance, to Mrs Anita Fursey for electron microscopy and to Mrs Pamela Cooper for isolating single organisms by micromanipulation.

\section{REFERENCES}

BAARs, J. K. (1930). Over sulphaatreductie door bacterien. Dissertation, W. D. Meinema, N.V., Delft.

Baker, F. D., Papiska, H. R. \& Campbell, L. L. (1962). Choline fermentation by Desulfovibrio desulfuricans. J. Bact. 84, 973.

Benziman, M. \& Abeliovitz, A. (1964). Metabolism of dicarboxylic acids in Acetobacter xylinum. J. Bact. 87, 270.

Buch, M. L., Montgomery, R. \& Ponter, W. L. (1952). Identification of organic acids on paper chromatograms. Analyt. Chem. 24, 489.

Butuin, K. R., Adams, M. E. \& Thomas, M. (1949). The isolation and cultivation of sulphate-reducing bacteria. J. gen. Microbiol. 3, 46.

Feigl, F. (1960). Spot Tests in Organic Analysis, 6th ed. Amsterdam and London: Elsevier Publishing Co.

Grossman, J. P. \& Postante, J. R. (1955). The metabolism of malate and certain other compounds by Desulphovibrio desulphuricans. J. gen. Microbiol. 12, 429.

Le Gall, J. (1963). A new species of Desulfovibrio. J. Bact. 86, 1120.

LitTlewood, D. \& Postgate, J. R. (1956). Substrate inhibition of hydrogenase enhanced by sodium chloride. Biochim. biophys. Acta, $20,399$.

Macpherson, R. \& Muner, J. D. A. (1963). Nutritional studies on Desulfovibrio desulfuricans using chemically defined media. J. gen. Microbiol. 31, 365.

MAgAsaniK, B. \& UMBarger, H. E. (1950). The separation and identification of ketoacids by filter paper chromatography. J. Am. chem. Soc. 72, 2308.

Miller, J. D. A. \& SAlEH, A. M. (1964). A sulphate-reducing bacterium containing cytochrome $c_{3}$ but lacking desulfoviridin. J. gen. Microbiol. 37, 419.

Postgate, J. R. (1951). The reduction of sulphur compounds by Desulphovibrio desulphuricans. J. gen. Microbiol. 5, 725.

Postgate, J. R. (1952). Growth of sulphate-reducing bacteria in sulphate-free media. Research, 5, 189. 
Postgate, J. R. (1953). On the nutrition of Desulphovibrio desulphuricans: a correction. J. gen. Microbiol. 9, 440.

Postgate, J. R. (1959). A diagnostic reaction of Desulphovibrio desulphuricans. Nature, Lond. 183, 481.

Postante, J. R. (1963). Sulfate-free growth of Clostridium nigrificans. J. Bact. 85, 1450.

Reio, L. (1959). A method for the paper-chromatographic separation and identification of phenol derivatives, mould metabolites and related compounds of biochemical interest, using a 'reference system'. Chromat. Rev. 1, 39.

Salei, A. M., Macpherson, R. \& Miluer, J. D. A. (1964). The effect of inhibitors on sulphate-reducing bacteria: a compilation. J. appl. Bact. 27, 281.

Senez, J. C. \& Pascal, M. C. (1961). Dégradation de la choline par les bactéries sulfatoréductrices. Z. allg. Mikrobiol. $1,142$.

Wruson, E. \& Wruson, D. (1959). Comprehensive Analytical Chemistry, vol. 1 A. Amsterdam and London: Elsevier Publishing Co. 